\title{
Repensando o esporte na educação física escolar a partir de Cagigal
}

Derli Juliano Neuenfeldt ${ }^{2}$

Marta de Salles Canfíeld ${ }^{3}$

\section{RESUMO}

Este artigo busca caracterizar um esporte para a Educação Física escolar fundamentando-se na compreensão de esporte-prática de Cagigal. Estabeleceu-se quatro princípios fundamentais: princípio cinestésico, pois o esporte é uma atividade predominantemente física; princípio lúdico, pois o esporte, antes de tudo, é um jogo; princípio agonístico, porque não há como negar a competição, e o princípio ético, que oferece valores norteadores para a conduta de quem pratica esporte. Acredita-se que o esporte-prática é uma tentativa de fornecer aos profissionais de Educação Física uma visão de esporte que contribua na formação dos alunos, ensinandoos a viverem em harmonia consigo mesmos e com a sociedade.

UNITERMOS: Educação Física escolar, esporte, educação.

\section{ABSTRACT}

RETHINKING THE SPORTIN THE SCHOOL PHYSICAL EDUCATION PROGRAM BASED ON CAGIGAL

This article proposes characterize a sport for the school Physical Education based in the: understanding of sport-practice of Cagigal. We settled down four fundamental principies: kinesthetic principie, because the sport is predominantly a physical activity; ludicrus principie, because the sport before everything is a game; agonistic principle, because there is no way to deny the competition and, the ethical principie, that offers values for the conduct of who practices sport. The sport-practice is an attempt ofsupplying to the professionals of Physical Education a sport vision that could contribute in the pupils' formation, teaching them to live in harmony with themselves and in society.
UNITERMS: Physical Education' classes, sport, education.

\section{APRESENTANDO O TEMA}

Atualmente, o esporte pode ser considerado o principal conteúdo da Educação Física escolar. Pereira (1997), em 1991/1992, ao investigar o cotidiano escolar de quatro escolas de ensino médio, dentre as quais três da rede de ensino estadual e uma da rede particular do Rio Grande do $\mathrm{Sul} / \mathrm{Br}$, percebeu que os principais conteúdos eram o futebol e o voleibol, desenvolvidos de forma recreativa sem um tratamento didático da teoria da Educação Física e configurados como práticas muito similares às que os alunos realizam fora do ambiente escolar. Tal evidência é justificada pelo fato de os professores escolherem os conteúdos pela popularidade e por não buscarem ampliar a cultura corporal dos alunos.

Também, em 1998, Molina Neto (1998) constatou, através de uma pesquisa realizada com vinte professores de Educação Física da rede pública de Porto Alegre/RS/Br, que esses programavam os conteúdos de suas aulas seguindo três orientações gerais para cada nível de ensino: atividades globalizadas até a $4^{\mathrm{a}}$ série do ensino fundamental; aprendizagem desportiva de $5^{\mathrm{a}}$ a $8^{\mathrm{a}}$ séries do mesmo nível de ensino, e prática desportiva para o ensino médio. Além disso, evidenciou que os conteúdos programados podem ser trabalhados dentro de duas perspectivas: do rendimento físico ou do lazer.

Portanto, o que se observa na Educação Física escolar é, de um lado, o esporte sendo desenvolvido como mera recreação e, de outro, uma prática esportiva iludida com os valores do esporte de rendimento. Dessa forma, o esporte, como conteúdo da Educação Física escolar, carece de reflexão. 
Ciente de que todo profissional de Educação Física : necessita de um suporte teórico para nortear a sua : prática pedagógica, este trabalho teve por objetivo repensar o esporte no contexto escolar, considerando- : o como conteúdo de uma disciplina comprometida : com o processo educativo. Portanto, propõe-se, através : de um pesquisa teórica (Demo, 1997) e a partir da * compreensão de esporte-prática de Cagigal, : caracterizar um esporte para as aulas de Educação : Física escolar, destacando-se princípios norteadores : da prática esportiva e que vislumbrem ações : educacionais.

Este estudo se justifica pelo fato do esporte não poder : se apresentar no meio escolar como uma prática assistemática, efêmera e inconseqüente. Ele não pode : limitar-se apenas ao fazer por fazer. Todo profissional : de Educação Física deve ter claro, ao lecionar, quais : são os objetivos que persegue com cada conteúdo : que desenvolve, qual é a contribuição que deve : oferecer e deixar aos seus alunos. Para que isso ocorra, : é fundamental que esse profissional tenha um : referencial teórico que lhe dê suporte.

Porém, a simples presença de um embasamento teórico norteador da prática pedagógica do profissional de Educação Física não é suficiente. É, portanto, necessário analisar quais são os princípios norteadores dessa fundamentação. Urge analisar qual é a postura que melhor convém para a Educação Física escolar, a fim de que ela atenda ao seu compromisso com a formação dos alunos. Portanto, deve-se ficar atento para o modelo de esporte a partir do qual o profissional de Educação Física desenvolve suas aulas, pois, de acordo com Bento (1987, p. 18), o esporte surge na escola marcado pelo esporte extra-escolar, cujos traços fundamentais residem no princípio de concorrência e da comparação objetiva dos resultados. Por isso, menciona que se deve partir de perguntas como: Quais os princípios do esporte? Qual a essência e quais os valores nele imanentes? Qual o significado do esporte na escola?

\section{ESPORTE-PRÁTICA: UMA COMPREENSÃO DE ESPORTE PARA A EDUCAÇÃO FÍSICA ESCOLAR}

O esporte-prática deve ser entendido, na Educação
Física escolar (EF), como um jogo (J) com características competitivas. Não se nega que outro tipo de jogo como, por exemplo, o de representação, venha a ser utilizado na escola como meio educacional. Porém, quando se fala no esporte-prática, está se fazendo referência a um jogo competitivo, essência de toda atividade esportiva (ver figura 1).

O esporte-prática identifica-se com uma visão particular de esporte. Em nossa sociedade, há duas formas básicas de se perceber o esporte (E): como espetáculo, em que o mais importante é conseguir a vitória; e como ação lúdica-esportiva, em que se busca a realização pessoal de quem o pratica. O esporteprática, como componente da Educação Física escolar (EF), identifica-se com a segunda concepção, pois acredita-se que a atividade lúdica tem maiores contribuições a oferecer aos nossos alunos. Portanto, o esporte-prática situa-se na área de interseção entre o esporte (E) e a Educação Física (EF), ficando evidente que o esporte que se almeja à Educação Física escolar não é o esporte-espetáculo, o qual fica alheio a ela.

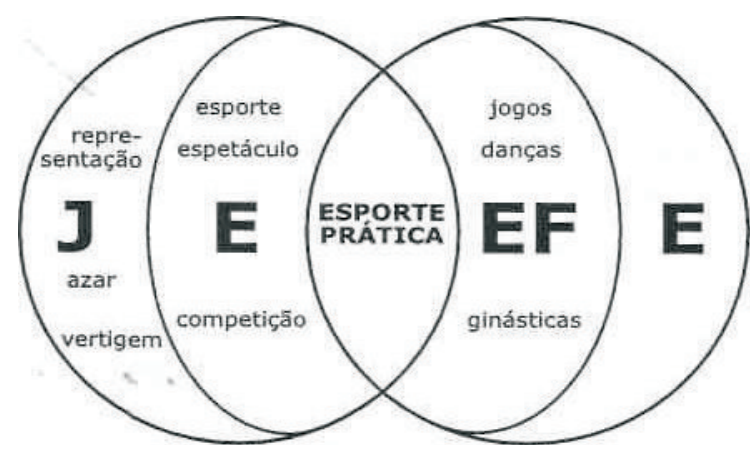

Figura 1 - Esporte-prática e a sua relação com a Educação. Adaptado da obra Esporte, Pedagogia e Humanismo (Cagigal, 1966,p.57).

O esporte-prática é apenas uma parcela dos conteúdos da Educação Física escolar e, ao salientá-lo neste trabalho, não se quer dar mais importância a ele do que aos demais conteúdos, apenas discutir e refletir sobre o seu compromisso no contexto escolar. O esporte-prática está inserido na Educação Física, e esta, por sua vez, na Educação (E). A Educação, neste contexto, refere-se às várias disciplinas existentes na escola, responsável pela formação dos alunos. Portanto, o esporte-prática apresenta-se 
comprometido com o processo educacional na medida em que é um conteúdo da Educação Física, disciplina que também deve estar comprometida com o desenvolvimento do projeto político-pedagógico da escola.

Tendo como base fundamental a compreensão de esporte-prática de Cagigal (1966), que considera o esporte um jogo, praticado de forma lúdicocompetitiva e com exercício físico, e que se converte na forma de esporte indicada para o meio educacional, estabelece-se quatro princípios que devem ser levados em consideração ao desenvolvê-lo na Educação Física escolar: o princípio cinestésico, o princípio lúdico, o princípio agonístico e o princípio ético.

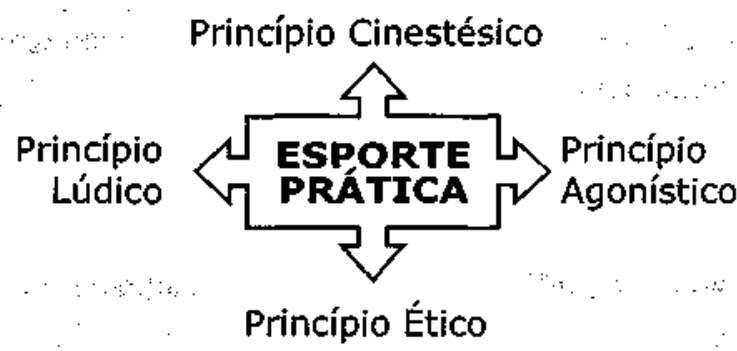

Figura 2 - Princípios do esporte-prática.

\section{a) PRINCÍPIO CINESTÉSICO}

Sabe-se que a escola valoriza, principalmente, os conteúdos que contribuem para a aprendizagem da cultura intelectual, ou seja, a leitura, a escrita, o cálculo. Isso é uma fato que ainda persiste, como pode-se perceber no art. 32 da última Lei de Diretrizes e Bases da Educação Nacional (n. ${ }^{\circ}$ 9394/1996). Há uma desvalorização das disciplinas que trabalham com a expressão humana, como, por exemplo, a Educação Artística e a Educação Física, porque os alunos precisam adquirir os conteúdos da disciplinas intelectuais, como se fossem as únicas importantes para a vida deles.

Assim sendo, por mudanças sociais que vão desde a diminuição de espaço físico até a exploração comercial dos ambientes propícios para a prática esportiva, o homem atual tem organizado sua vida de uma forma em que cada vez se movimenta menos. Ele tem deixado de sentir que necessita do movimento, pois já se acostumou com o conforto advindo da tecnologia e, consequentemente, com o próprio sedentarismo. Porém, o homem, para Cagigal (1979), vive em movimento e parece que não subsistiria plenamente como tal sem a capacidade de exercitação. Ele está capacitado a mover-se, foi feito para mover-se.

O princípio cinestésico do esporte-prática quer justamente chamar a atenção para a importância do movimento para a vida do homem. Por isso, deve-se tratar o esporte, no contexto da Educação Física, como exercício físico. Isso implica em conceber o esporte como uma atividade predominantemente física, tal como Cagigal entende, buscando fazer o aluno sentir que o movimento faz parte da sua natureza humana e que deve acompanhar o homem por toda a sua vida.

Pode-se destacar dois aspectos fundamentais para justificar a necessidade de tornar a prática esportiva um elemento indispensável na vida dos alunos: a) o combate ao sedentarismo e a todos os males de ordem fisiológica e psicológica ocasionados pela inatividade física e b) a possibilidade que o esporte oferece de proporcionar a realização pessoal do praticante e a fuga da padronização de hábitos impostos pela sociedade industrial.

Concorda-se com Cagigal (1981) quando ele aponta que o esporte é extremamente útil numa sociedade em que o homem se exercita cada vez menos, pois as doenças graves do momento, que têm levado à alta porcentagem de mortalidade, são as cardiovasculares, pelas quais o sedentarismo, o desequilíbrio, a tensão física e a inatividade física possuem grande responsabilidade.

Contudo, para que o esporte volte a ser praticado, é necessário que, durante o período escolar, os alunos sejam conscientizados da importância da prática esportiva para a vida. O professor de Educação Física de incumbir-se em mostrar que o esporte pode trazer, para aqueles que o praticam, benefícios desde a ordem fisiológica, psicológica, até educativa. É necessário fazer com que os alunos "sintam" os benefícios que o esporte pode proporcionar, as alterações fisiológicas que ocorrem e, compreendam também que o esporte é um amplo campo de relações sociais. A 
Educação Física escolar tem o compromisso de buscar incorporar o esporte na vida de seus alunos. Estes devem, ao saírem da escola, levar consigo uma imagem : boa do esporte como opção de atividade para o seu : lazer. No entanto, em nossa realidade social, a prática : do esporte vem deixando de ser uma atividade do : lazer, perdendo espaço para os programas televisivos : e para os jogos eletrônicos. Portanto, ao se desenvolver : o esporte, atento ao princípio cinestésico, deve-se : buscar transmitir aos alunos que a prática esportiva : pode suprir suas necessidades em termos de: movimentos e que seus benefícios vão muito além : de muitas práticas repetitivas encontradas na maioria : das academias de ginástica e musculação. É : extremamente necessário lutar contra o processo de : "aesportivação", salientado por Cagigal, já na década : de sessenta do séc. XX, caracterizado pela ausência : de exercício físico e pela negação da prática esportiva : na vida das pessoas.

\section{b) PRINCÍPIO LÚDICO}

O esporte, segundo Cagigal (1966), antes de tudo, : deve ser um jogo, entendido como sinônimo de ludicidade. Isso porque, para Cagigal (1981), o : movimento mais enriquecedor é o de caráter : espontâneo e lúdico.

O princípio lúdico do esporte-prática propõe que se mantenha a essência lúdica, e que o esporte leve em consideração as características do jogo, que são: ser uma atividade voluntária, ter sentido em si mesmo, possuir regras, ser um mundo à parte e gerar dúvida quanto ao resultado.

Tais características tornam-se difíceis de serem encontradas na medida em que se percebe que o: esporte na Educação Física, pela sua vinculação à : educação, passou a absorver o modelo de educação que educa para o amanhã (Cagigal, 1981). Nesse sentido, sabe-se que a Educação Física é desprestigiada porque a própria escola questiona a sua "utilidade para a vida futura dos alunos". Assim sendo, procurase, muitas vezes, encontrar uma forma de ensinar os conteúdos das outras disciplinas através dos jogos, buscando-se assim, torná-los "úteis", como se eles não tivessem, em si mesmos, valor algum.
O fato de o jogo ser considerado uma atividade improdutiva não significa que não oferece nenhum benefício para o aluno. Ele é improdutivo porque não visa ao futuro, o importante é o momento, de modo que o fato de o aluno ganhar ou perder não vai alterar em nada a sua vida. Não há como negar a contribuição que o jogo oferece ao desenvolvimento da expressão corporal do aluno, no estabelecimento de relações sociais, no desenvolvimento da personalidade, e até dependendo da intensidade e regularidade, no melhoramento do sistema fisiológico.

Além disso, o simples fato de o aluno jogar espontânea e voluntariamente, é elemento suficiente para atribuir ao jogo um valor inestimável, pois representa a fuga da mecanização e da padronização de hábitos. Nesse sentido, Cagigal (1979) ressalta a necessidade de a nossa supercivilização, devido ao condicionamento da técnica e da economia, buscar o renascimento da cultura de qualidades primitivas e a volta do elemento lúdico.

Quanto ao fato do esporte possuir regras, é necessário que elas sejam entendidas pelos alunos não como repressoras do poder criativo dos jogadores, mas como uma necessidade, para que o jogo ocorra em situação amigável. A questão mais freqüente ao se discutir as regras dos esportes, na Educação Física escolar, é que, por elas serem pré-determinadas por uma federação internacional e elaboradas para atletas de alto nível, precisam ser adaptadas, em prol de uma Educação Física inclusiva e não discriminatória. Porém, o que deve ser entendido: não são as regras que são ruins, mas a forma como são usadas. Se a concepção de esporte que prevalece é aquela que valoriza o resultado acima de tudo e se a cobrança por resultado for muito grande, o aluno pode vir a fazer uso das regras ou a desvirtuá-las para tirar vantagens, para buscar a vitória por meios que não se limitam apenas na sua habilidade de jogar.

Para Huizinga (1996) e Caillois (1958), apesar de o jogo possuir regras, as leis e costumes da vida cotidiana perdem a validade, o que reforça a afirmação que o jogo é um mundo próprio. Contudo, é difícil imaginar que os alunos, ao irem para a aula de Educação Física, esquecem todas as relações que possuem com seus 


\begin{abstract}
(1) colegas. Basta deixar que eles se dividam em equipes : para se perceber as relações de afetividade existentes, : e que muitas vezes influenciam muito a formação dos : times. Admitir que as leis e os costumes da vida : cotidiana perdem sua validade, é ratificar atitudes: como a de muitos jogadores que aproveitam o esporte : para descarregar, nos seus adversários, suas tensões : do dia-a-dia. Tal fato ocorre porque o jogador : desconsidera que os seus adversários são, na verdade, : seus amigos e, no caso da Educação Física escolar, : seus colegas de classe. Portanto, tanto no jogo como : fora dele, deve-se recomendar aos alunos que: mantenham uma conduta única, pois não se pode : esquecer que o esporte é um espaço de convívio social : e que as leis que regem a sociedade continuam a valer.

O jogo pode ser considerado um mundo à parte na : medida em que o importante, no momento em que : se está jogando é o :

jogo deixa de divertir quem, por estar bem preparado ou por ser mais hábil, ganha sem esforço e infalivelmente.

O esporte-prática que se identifica como um jogo, uma atividade lúdica, ao ser desenvolvido na Educação Física escolar, atento para o princípio lúdico, deve buscar e proporcionar momentos agradáveis de convivência entre os alunos, momentos que proporcionem prazer, de forma que o sorriso permaneça estampado no rosto deles. Para isso, devese fazer o aluno sentir, através da prática esportiva, que jogar é sinônimo de alegria e de satisfação pessoal. Por isso, na denominação "esporte-prática", a adjetivação estabelecida pela palavra "prática" serve justamente para salientar que o importante do esporte está em praticá-lo, nos momentos de convivência que são estabelecidos. Assim sendo, mesmo se buscando um resultado positivo, o fato de se estar perdendo não deve afetar o prazer de jogar.
\end{abstract}

$\mathrm{Na}$ denominação jogo e nada mais. Toda : "esporte-prática", a adjetivação deve estar voltada para o : estabelecida pela palavrajogo. Os jogadores: "prática" serve justamente para devem atentar que o jogo : salientar que o importante do é um momento quase: esporte está em praticá-lo, nos sagrado, portanto, não : momentos de convivência que ${ }_{\text {ou }}$ se deve interrompê-lo: são estabelecidos.

bandoná-lo sem uma causa justa, como, por exemplo, : pelo fato de se estar perdendo. Além disso, o aluno : deve compreender que, no jogo, por ser: determinado por regras, ele só poderá contar: consigo mesmo e com seu time, nada mais, : compreendendo, pois, que se trata de um: momento isolado do resto do mundo.

Os alunos também precisam compreender que faz : parte do jogo ele se desenvolver de forma tensa. : Conforme Cagigal (1981), o fato de não se saber o : que pode acontecer ou qual vai ser o resultado do : jogo pode ser um dos estímulos que levam as pessoas : a ter uma satisfação pessoal no esporte, tanto como : praticantes quanto como telespectadores. Para manter : esta tensão, na prática esportiva, as forças dos : adversários devem estar equilibradas para que cada : um possa defender sua oportunidade até o fim. $\mathrm{O}$ :

\title{
C) PRINCÍPIO AGONÍSTICO
}

O fato do esporte ser uma atividade competitiva é outro princípio fundamental que deve ser foco da atenção dos profissionais de Educação Física ao trabalharem com ele. Cagigal (1979) aponta que a competição, por seu caráter motivante, é indispensável em uma verdadeira atividade esportiva. a

Hoje a competição está cada vez mais presente em nossa sociedade. Compete-se em busca de uma vaga para a criança poder estudar na escola, disputa-se uma vaga no vestibular, um emprego, enfim, competese para conseguir sobreviver. Muitos tentam apontar a competição como algo negativo, porém, pretender formar um aluno alheio à sociedade competitiva em que se vive é transmitir uma visão distorcida de mundo. É formar um cidadão apático que provavelmente sentirá enormes dificuldades para se adaptar quando passar a ter contato com a realidade social. Logo, a prática saudável do esporte ou jogo pré-esportivo, manifestando sempre uma valorização competitiva, pode servir como meio para a criança aprender a realidade da sua própria limitação.

O esporte é uma ótima forma de os alunos aprenderem que a vida não é feita só de vitórias e que nem sempre 
se consegue tudo o que se almeja. O esporte os põe : frente à derrota, o que os obriga a aprenderem a : superar suas frustrações. Cagigal (1981, p. 203) nos : diz: "Uma equipe esportiva é uma aula vivente e : ambulante de espontânea aprendizagem dos ajustes : da realidade e da vida social".

Como o esporte pode ser considerado um reflexo : dos valores da sociedade (Caillois, 1958; Diem, 1966; : Cagigal, 1966), deve haver uma preocupação do : profissional de Educação Física para que a : exacerbada competição existente na vida da: sociedade contemporânea, que se evidencia no : esporte-espetáculo, não sirva de exemplo para o : esporte desenvolvido na aula de Educação Física : escolar.

A competição, no momento que é incentivada em : demasia, pode comprometer as possibilidades : educativas e o prazer da prática esportiva na Educação : Física escolar, pois, se a cobrança pela vitória for : elevada, os alunos podem acabar esquecendo que os : adversários são seus colegas e acabar desrespeitando : as regras, podendo, inclusive, aparecer manifestações agressivas.

É preciso ensinar aos alunos a competição saudável, a que permite que o jogo se torne atrativo, que ensine aos alunos a atuarem em conjunto e que jamais sirva para estabelecer "rankings" de classificação e, : consequentemente, discriminações entre eles. Assim, : a competição no esporte-prática deve ser desenvolvida de maneira que não ponha em risco o princípio lúdico, ou seja, não interfira no prazer de se praticar o jogo.

O profissional de Educação Física, pela formação que possui, deve ser capaz de distinguir o nível de competição que pode exigir de seus alunos daquele exigido em torneio e campeonatos profissionais, que são transmitidos, diariamente, pela TV. No contexto escolar, há a necessidade de que os alunos percebam o elemento competitivo do esporte no seu sentido primeiro, ou seja, como um fator motivacional. A principal competição a ser incentivada é a do aluno consigo mesmo na busca da superação de seus próprios resultados.
Portanto, ao se pensar no princípio agonístico do esporte-prática, concorda-se com Cagigal (1972), que menciona que o homem não precisa deixar de ser competidor. O importante é que essa competição seja desenvolvida de forma pacífica e fecunda à convivência e ao jogo. Para isso, o esporte jamais deve deixar de ser visto como jogo. Se mantiver essa condição, manterá as garantias humanísticas que podem converter verdadeiramente o esporte em um positivo elemento para a recuperação do equilíbrio do homem do nosso tempo.

\section{d) PRINCÍPIO ÉTICO}

Partindo do princípio de que o homem é um ser social (Cagigal, 1981; Leontiev 1969; Laraia; 1992) e possui a vida norteada por valores (Cagigal, 1981), deve-se considerar que o aluno chega à escola inacabado, necessitando constituir-se, firmar seus valores e, o "acabamento", é função dos educadores.

Dessa forma, a Educação Física escolar, como componente curricular do processo educativo, também deve preocupar-se com a formação da moral, da ética, da cidadania de seus alunos. A preocupação com os valores morais que permeiam suas aulas reforça o papel de educador exercido pelo profissional de Educação Física junto à escola, pois a formação da personalidade é um campo comum a todos os educadores.

O princípio ético do esporte-prática propõe que, durante o trabalho com os esportes, reflita-se e discutase com os alunos quais são atitudes corretas ao se praticar algum esporte, o que é função da ética, buscando-se estabelecer valores que devem nortear a conduta dos alunos na prática esportiva, ou seja, estabelecer uma moral esportiva.

Acredita-se que, através dos esportes, seja possível desenvolver uma educação que, a partir da reflexão ética, propicie a formação, em nossos alunos, de uma consciência da necessidade da existência de direitos, deveres e proibições para que a vida em sociedade desenvolva-se de forma harmônica. Para que isso ocorra, conforme Cagigal (1972), o pedagogo deve aproveitar o esporte dentro da conjuntura atual como elemento educativo, estruturador da personalidade. É necessário descobrir, nas estruturas do próprio 


\begin{abstract}
(1) esporte, os elementos educativos que podem ajudar : no amadurecimento da personalidade do aluno.

prol de um convívio comum, e também ajudá-lo a estabelecer-se em um grupo humano de convivência, a viver em sociedade e a dialogar com o mundo que As manifestações agressivas que podem vir a aparecer : durante a prática esportiva, devido ao contato físico : fazer parte da maioria dos esportes, é um exemplo de : situações que devem ser colocadas em pauta pelo: profissional de Educação Física durante a aula e no : momento em que ocorrer. Dificilmente um aluno:

o cerca. Nesse contexto, mais que uma simples prática recreativa, higienista, o esporte apresenta-se como um ótimo meio para a criança, o adolescente e o adulto aprenderem a lidar com suas fraquezas, a serem responsáveis pelos seus atos e a pensarem nas consequências das suas ações.
\end{abstract} agredido não reagirá à agressão que sofreu, pois este : sente-se desrespeitado enquanto ser humano. Portanto,: deve-se conscientizar os alunos para que evitem de : cometer faltas, pois elas não devem ser usadas em : benefício do resultado final. Deve-se aproveitar, de : acordo com Neuenfeldt (1999), essas situações para: levantar questões com os alunos, sobre até que ponto, : para se evitar um gol, : uma cesta ou mais um :

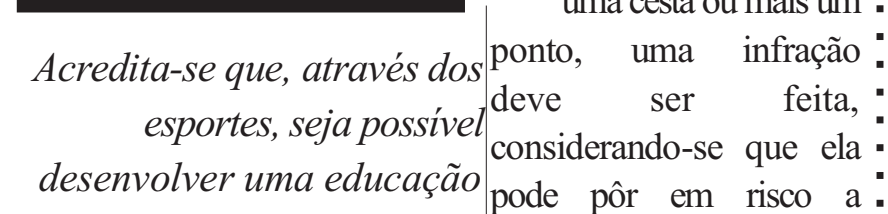
que, a partir da reflexão ética, integridade fisica de seu: propicie a formação, em nossos colega.

alunos, de uma consciência da necessidade da existência de Outra contribuição do : direitos, deveres e proibições esporte para a formação : para que a vida em sociedade dos alunos pode ser: de estabelecida pelo fato de : desenvolva-se deforma ele ser uma conduta : harmônica. regrada, o que caracteriza : um hábito de autocontrole. Através do esporte, : aprende-se a dialogar com a vida, com outro ser: humano, de uma maneira civilizada ou cívica, : respeitando o outro e seus desejos, com uma: aceitação jurídica dos mesmos direitos. "O : autocontrole é o primeiro grande princípio da: convivência humana. No esporte, esse : autocontrole se desenvolve num ambiente: eminentemente lúdico, o qual lhe priva da servidão : ambiental de uma opressão rígida, imposta, implacável" : (Cagigal, 1976, p. 107).

A prática esportiva também pode contribuir para que : o aluno aprenda a assimilar futuras frustrações, na : aprendizagem em que, muitas vezes, é necessário : desfazer-se de muitos de seus impulsos pessoais em

Outro aspecto que o profissional de Educação Física não pode deixar de discutir com seus alunos é a questão da derrota nos esportes. Cagigal (1972, p. 73) nos diz: "A melhor herança que pode deixar um pai a seu filho ou um educador a seu discípulo é a firmeza de aspirar o triunfo e a capacidade de assimilar a derrota". Portanto, a frase "saber perder" diz muito mais que uma atitude de elegância. Saber perder é ser capaz de compreender e estar capacitado a enfrentar as dificuldades da vida. Mas, aceitar a derrota não significa que se deve deixar de buscar a vitória. E, além de serem preparados para a derrota, é necessário que os alunos percebam que, quando vencem, do outro lado, não há derrotados, mas adversários que são indispensáveis para que o esporte exista. Deve-se ensiná-los a respeitarem os perdedores.

O esporte-prática, ao levar em conta o princípio ético, deve ter como ponto de partida o reconhecimento da natureza humana do adversário, num contexto em que se saiba valorizar o vencedor e respeitar o perdedor, em que jogar com os amigos seja mais importante do que vencer o jogo, em que, ao se terminar o jogo, a vontade de reiniciar permaneça. Para que isso ocorra é indispensável, destaca Cagigal (1966), o papel fundamental do profissional de Educação Física, que deverá levar seu aluno a compreender que o esporte é uma forma de conceber a vida, que deve ser transmitido axialmente por um hábito de lealdade. O educador deve ser fiel a seus princípios, às normas e inflexível na exigência do "fair play", ou seja, do jogo limpo. Pois, se não for assim, o que se pode esperar do sentido esportivo e, como consequência, da formação ética dos alunos de um profissional que, por exemplo, em busca da vitória em uma competição engana aos organizadores sobre a idade de seus alunos? Será que há um educador? 


\section{CONSIDERAÇÕES FINAIS}

O esporte-prática é uma tentativa de resgatar os valores que outrora nortearam o esporte e que, de certa : forma, estão adormecidos por irem contra os que : vigoram, atualmente, na sociedade. Acreditando em : seu valor formativo, busca-se mostrar que é possível : pensar um esporte que seja fonte de alegria, de fruição, : que seja espaço de convívio social, de troca de : experiências e que possibilite a formação do caráter.

Um dos princípios fundamentais do esporte-prática é que ele seja um jogo, concebido como uma manifestação lúdica. A importância de se proporcionar a ludicidade, que, no esporte deveria existir por : excelência, deve-se ao fato de que, em virtude das : mudanças sociais ocorridas a partir da Revolução Industrial, da crescente urbanização e do : desenvolvimento da tecnologia, o homem de nosso tempo já não sabe mais jogar. Sua vida passou a ser : dominada pela seriedade do trabalho, por uma rotina de atividades repetitivas em que seu potencial criativo não é mais estimulado. Desenvolver o esporte de : forma lúdica significa possibilitar ao aluno, vítima de : um dia-a-dia escolar marcado pelas cobranças dos : conteúdos intelectuais e pela vida sedentária, realizar : uma atividade em que não precisa preocupar-se com : a possibilidade de vir a obter um resultado negativo e, ao mesmo tempo, resgata o seu papel de protagonista.

Outro objetivo deste trabalho, ao estabelecer o princípio agonístico, foi desmitificar que a competição possui valor negativo e que, o esporte, por ser competitivo, reforça a competição em outras instâncias. Não é possível conceber um esporte sem competição, a qual é fonte de estímulo e motivação que desperta o desejo de superação. A competição é elemento constituinte do esporte. Também faz parte do esporte ganhar ou perder, logo, almejar a vitória não é descrédito para nenhum jogador. Dentre os cuidados necessários ao se tratar da competição destacam-se a garantia de que a busca pelo resultado não desvirtue a conduta do jogador, a necessidade de o jogador compreender que o adversário nada mais é que seu colega, seu amigo, não sendo, pois, conveniente, nenhuma conduta desleal.
O princípio cinestésico do esporte-prática tem o objetivo de mostrar aos alunos a necessidade e a importância de se fazer um exercício físico regularmente, levando-os a perceber que o esporte pode oferecer, além de benefícios fisiológicos, riquíssimas oportunidades de relações sociais, de expressão corporal e criativa, prazer e satisfação pessoal.

Dessa forma, é imprescindível que, ao se trabalhar com o esporte na Educação Física, busque-se alcançar três objetivos básicos. Em primeiro lugar, é necessário ensinar os alunos a praticarem o esporte-prática. Esse ensino denota toda uma caminhada do aluno em sua vida escolar de forma que aprenda as mais variadas formas esportivas, suas técnicas, táticas e regras. Em segundo lugar, é necessário que o aluno tenha consciência da importância da prática esportiva para a sua vida, devendo, para isso, ser salientados os possíveis benefícios fisiológicos, psicológicos, sociais, afetivos e morais do esporte. O terceiro objetivo, que é a aquisição do hábito da prática esportiva, ocorrerá como conseqüência do alcance do objetivo anterior, pois se tornará uma necessidade quando o aluno alcançar um nível suficiente de consciência da importância da prática esportiva.

Um alerta que se faz aos profissionais de Educação Física é que não vejam o esporte apenas como cultivo do corpo. A limitação do esporte a aspectos fisiológicos ou à aprendizagem das técnicas esportivas não é justificativa suficiente para a sua presença no contexto escolar. Por isso, em tempos em que se questiona o valor educacional da Educação Física na escola, é de vital importância o desenvolvimento do princípio ético, presente no esporte-prática.

Dessa forma, o profissional de Educação Física não pode mostrar-se alheio ao processo construtivo e consolidativo da personalidade de seu aluno. Há necessidade de explorar as possibilidades de que o esporte dispõe para o desenvolvimento de atitudes morais. Honestidade, lealdade, respeito à integridade física e moral, cooperação são valores que podem ser trabalhados através do esporte, processo que pode iniciar com o entendimento do aluno sobre o significado de "fair-play". Portanto, o educador deve 
-

ter claro que os alunos são muito parecidos na forma de praticar o esporte e que a diferença em suas atitudes será o reflexo da educação recebida.

Mesmo com todo o avanço tecnológico que os alunos possam ter acesso, auxiliando-os na aprendizagem, a : presença do educador mantém-se como uma necessidade. $\mathrm{O}$ educador, convicto de seus valores, é capaz de formar o aluno, de lhe dar uma orientação ética para que possa viver melhor em sociedade. Por isso, os profissionais de Educação Física deveriam se fazer mais presentes nos setores responsáveis pela divulgação do esporte. Tal fato torna-se necessário quando se percebe que, cada vez mais, o esporteespetáculo é contemplado pela mídia como se fosse o único modelo existente. É preciso transmitir que a prática do esporte pode ser norteada por outros valores, e, nesse sentido, o esporte-prática vem para suprir essa carência. Logo, cabe aos profissionais de Educação Física divulgá-lo.

Portanto, considera-se este trabalho uma tentativa de refletir, a partir das evidências colhidas na literatura, sobre o fenômeno ESPORTE em nossa sociedade, bem como de propor uma concepção de esporte que possa contribuir tanto para a formação dos alunos como para fazer com que o esporte venha a tornarse uma necessidade cada vez mais presente na vida de todo ser humano.

\section{REFERÊNCIAS BIBLIOGRÁFICAS}

BENTO, J. O. Desporto: "Matéria de Ensino". Lisboa: Editorial Caminho S.A., 1987. 138 p. Coleção Desporto e Tempos Livres.

BRASIL. Lei de Diretrizes e Bases da Educação Nacional $n^{\circ}$ 9394. Brasília: Senado Federal Subsecretária Especial de Editoração e Publicações, p. 15-24, dezembro de 1996.

CAGIGAL, J. M. Deporte, pedagogia y humanismo. Madrid: RAMOS -Artes Gráficas. 1966.123 p Deporte, Pulso de Nuestro Tiempo. Madri: Artes Gráficas Lillo. 1972.179 p.
Deporte e agresión. Barcelona: Editora Planeta, S.A. 1976.190 p. _Cultura intelectual e cultura física. Buenos

Aires: Editorial Kapelusz, S.A. 1979. 118 p. Oh Deporte (Anatomia de un Gigante). Spain: Editorial Mihón. 1981. (Colección KINÉ de Educación y Ciência Deportiva). 234 p.

CAILLOIS, R Teoria de losjuegos. Barcelona: Editorial Seix Barrai, SA. 1958.194 p. Tradução de Ramón Gil Novales. DEMO, P. Pesquisa: Princípio científico e educativo.

5. ${ }^{\text {a }}$ ed. São Paulo: Cortez, 1997. 120 p.

DIEM, C. História de los Deportes. Barcelona: Luis de Caralt Editor. Vol. 1.1966. 479 p.

HUIZINGA, J. Homo Ludens: Ojogo como elemento da cultura. 4.' ed. São Paulo: Perspectiva/Editora da USP. 1996.243 p. LARAIA, R de B.

Cultura: Um conceito Antropológico.

6. ${ }^{a}$ ed. Rio de Janeiro, RJ: Jorge Zahar Editor

Ltda., 1992.116 p. LEONTIEV, A. N.

ElHombrey Ia Cultura. México:

Editorial Grijalbo, S.A. p. 07-48. 1969.

MOLINA NETO, V. A prática dos professores de Educação Física das escolas públicas de Porto Alegre. Movimento. Ano V. N. ${ }^{\circ}$ 9, p. 31-46,1998. NEUENFELDT, D. J. Esporte na Educação Física Escolar: Possibilidades Educacionais. Kinesis. N. ${ }^{\circ}$ 21. p. 233-246.1999. PEREIRA, F. M. O cotidiano escolar e a educação

fisica necessária. 2. ${ }^{\text {a }}$ ed. Pelotas: Ed. Universitária/UFPEL. 1997.284 p.

\section{NOTAS}

: 1. Dissertação de Mestrado apresentada ao Programa de Pós-graduação em Ciência do Movimento Humano - CEFD/UFSM.

: 2 . Professor de Educação Física da Rede Estadual de - Ensino do Rio Grande do Sul e Prof. da disciplina de - História da Educação Física do Curso de Educação - Física da UNIVATES/RS.

3. Doutora em Motricidade Humana. 